\title{
The Evolution of Management of Acute Coronary Syndromes (Unstable Angina and Non-ST Segment Elevation Myocardial Infarction): Part I
}

\author{
By C. Richard Conti, MD, MACC, Editor-in-Chief
}

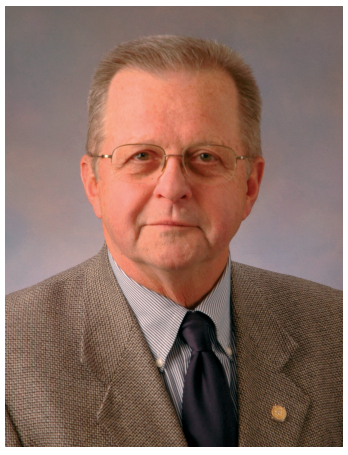

As I advanced through medical school at Johns Hopkins, and throughout my subsequent training, I was constantly reminded of the contributions made to medicine by our predecessors. Many of whom were at Johns Hopkins, but many were not. As I continue active involvement in the education of medical students and physicians, it seems to me we have not done a good job of relating the history of how the modern management of patients with cardiovascular disease developed to our students, house staff, and fellows.

Key words: acute coronary syndrome, management, history

\section{Introduction}

My goal in this editorial is to reflect on how we arrived at where we are today. I will use acute coronary syndromes (ACSs) as an example, and will try to emphasize for the reader some, not all, of the individuals who made major contributions that eventually evolved into the current management of these syndromes.

Obviously, what we know at present is a great deal more than when angina pectoris was first described by Heberden.

\section{The Present}

In 2008, patients presenting with acute coronary syndromes generally present as 1 of 2 clinical scenarios - new onset of severe angina (usually recurrent rest angina), or crescendo angina (accelerating chronic angina). If cardiac enzymes or troponins are normal, the syndrome is called unstable angina. If the cardiac enzymes or cardiac markers are positive, the patients are designated as either non-ST-segment elevation myocardial infarction, or ST-segment elevation myocardial infarction depending on the electrocardiogram (ECG) changes. Risk stratification of these patients can be performed easily on admission to the hospital since subsequent therapy will be determined by patient risk.

I do not plan to dwell on the current management of ACSs since this area is well known to all cardiologists, and guidelines clearly outline the proper approach to the management of this common problem that accounts for over 1 million hospitalizations per year. ${ }^{1}$ Acute management strategies have been worked out quite well and are fairly well standardized. However, it has become obvious that this is not a homogeneous population, and there are many clinical variables associated with this syndrome that sometimes make management decisions difficult in the individual patient. These variables include ECG changes, CKMb +/-, troponins +/-, CRP +/-, left ventricular (LV) function normal/abnormal, and coronary angiographic pathology that may be different based on extent, location, severity, and morphology.

\section{The Past}

Winston Churchill was reported to have said, "The farther backward you can look, the farther forward you are likely to see.”

\section{Pathologic Observations}

In 1858, Rudolph Virchow proposed that injury to the inner wall of a blood vessel, possibly caused by fat, might lead to inflammation and secondary plaque formation, a notion very close to present day theory. ${ }^{2}$

In 1937, Sampson, Eliaser, and Feil hypothesized that gradually forming thrombosis could explain the pain of "pre-infarction angina." They advised that “. . . effort should be made to improve coronary blood flow." 3,4 This set the stage for myocardial revascularization 31 years later.

In 1966, Constantinides described plaque fissuring in fatal coronary artery disease. ${ }^{5}$ He hypothesized that breaks in the lining of plaques was a precipitating cause of acute coronary thrombosis.

In 1983, Earling Falk, a Danish pathologist, proposed that embolization from plaque rupture might result in microinfarctions. ${ }^{6}$ Clinically, these should be the patients 
with troponin elevations without much else indicating acute myocardial infarction.

In 1985, Davies and Thomas initiated the concept of vulnerable plaques. ${ }^{7}$ These plaques had thin fibrous caps over a lipid pool containing inflammatory cells. When these plaques rupture, acute myocardial infarction, sudden cardiac death, or crescendo angina can ensue.

In 1999, Russell Ross proposed that coronary disease was an inflammatory process. ${ }^{8}$ Ross's observations over the course of several years revolutionized research in the origins of human atherosclerosis.

\section{Some Early Clinical Observations}

William Heberden, in 1772, writing about stable angina, may have been the first physician to describe crescendo angina. He stated that, "After it has continued some months, it will not cease so instantaneously upon standing still, and will come on not only when the persons are walking but when they are lying down." 9

Sir William Osler, in one of his Lumleian lectures in 1910, commented that myocardial infarction was often preceded by a progression of angina symptoms. ${ }^{10}$ Thus, this is possibly the origin of the term "pre-infarction angina."

Peter Gazes, in 1973, in a prospective 10-year study of unstable angina patients showed that an abnormal ECG, (e.g., ST-segment depression), was a risk factor. ${ }^{11}$

\section{Pathophysiology}

Paul Wood, in 1948, working in London, wrote that in patients with acute coronary insufficiency “. . . physiologically the coronary circulation is insufficient to meet the full demands of the myocardium at rest yet sufficient to prevent myocardial infarction." ${ }^{12}$ Many have proven that statement to be correct.

Attilio Maseri, several years later in 1975, reported observations of dynamic coronary artery obstruction and the role of coronary artery spasm in patients with acute coronary syndromes. ${ }^{13}$ This was a seminal observation of great clinical importance previously not given much credence.

To Be Continued . . .

Next month I will continue this editorial with comments on early diagnostic studies, early general management, clinical trials, and challenges for the future.

\section{References}

1. Anderson JL, Adams CD, Antman EM, Bridges CR, Califf RM et al.: ACC/AHA 2007 guidelines for the management of patients with unstable Angina/Non-ST-elevation myocardial infarction-executive summary: a report of the American College of Cardiology/American heart association task force on practice guidelines. J Am Coll Cardiol 2007;50:652-726

2. Simmons J: Rudolph Virchow and the cell doctrine. The Scientific 100-A Ranking of the Most Influential Scientists, Past and Present. Secaucus, NJ: Carol Publishing Group; 1996; 88-92

3. Sampson JJ, Eliaser M Jr: The diagnosis of impending acute coronary artery occlusion. Am Heart J 1937;13:675-686

4. Feil H: Preliminary pain in coronary thrombosis. Am J Med Sci. 1937;193:42-48

5. Constantinides P: Plaque fissuring in human coronary thrombosis. J Atheroscler Res 1966;6:1

6. Falk E: Plaque rupture with severe preexisting stenosis precipitating coronary thrombosis: characteristics of coronary atherosclerotic plaques underlying fatal occlusive thrombi. $\mathrm{Br}$ Heart J 1983;50:127

7. Davies MJ, Thomas AEC: Plaque fissuring: the cause of acute myocardial infarction, sudden ischemic death, and crescendo angina. Br Heart J 1985;53:363

8. Ross R: Atherosclerosis. An inflammatory disease. $N$ Engl J Med 1999;340:115-126

9. Heberden W: Some account of a disorder of the breast. Med Trans Coll Physicians Lond 1772;2:59

10. Osler W: The Lumleian lectures on angina pectoris. Lancet 1910;1:697-701

11. Gazes PC, Mobley EM, Faris HM, Duncan RC, Humphries GB: Preinfarction (unstable) angina-A prospective study - ten year follow-up. Prognostic significance of electrocardiographic changes. Circulation 1973;48:331-337

12. Wood P: Therapeutic application of anticoagulants. Trans Med Soc Lond 1948;66:80

13. Maseri A, Mimmo R, Chierchia S, Marchersi C, Pesola A, et al.: Coronary spasm as a cause of acute myocardial ischemia in man. Chest 1975;68:625 